\title{
Knowledge, Reading Practice and Associated Factors of Nutrition Labeling on Packaged Food Among Consumers in Addis Ababa, Ethiopia
}

\author{
Esayas Feyisa ${ }^{1,}$, Robert Wondimu ${ }^{2}$, Zalalem Kaba ${ }^{3}$ \\ ${ }^{1}$ Addis Ababa City Health Bureau, Food Medicine and Healthcare Administration and Control Authority, Health and Health Related Facility \\ Inspection, Addis Ababa, Ethiopia \\ ${ }^{2}$ SendafaBeke Town Health Office, Sendafa Beke Town, Ethiopia \\ ${ }^{3}$ East Wollega Zonal Health Office, Water, Sanitation, Hygiene and Neglected Tropical Diseases Program, Nekemte, Ethiopia
}

Email address:

esayasfeyissa@gmail.com (E. Feyisa),robertwondimu2021@gmail.com (R. Wondimu), kabazalalem@gmail.com (Z. Kaba)

${ }^{*}$ Corresponding author

\section{To cite this article:}

Esayas Feyisa, Robert Wondimu, Zalalem Kaba. Knowledge, Reading Practice and Associated Factors of Nutrition Labeling on Packaged Food Among Consumers in Addis Ababa, Ethiopia. Journal of Food and Nutrition Sciences. Vol. 9, No. 2, 2021, pp. 48-56. doi: $10.11648 /$ j.jfns.20210902.13

Received: March 20, 2021; Accepted: April 1, 2021; Published: April 23, 2021

\begin{abstract}
Nutrition labeling is a valuable tool in learning how to apply nutrition information and help to food choices. Consumption of processed and packaged food is common in low and middle income countries like Ethiopia. But, the level of knowledge and reading practice of nutrition labeling among supermarket shoppers is not known in the study area. The objective of the study was to assess the knowledge, reading practice and factors associated to nutrition label on packaged food among consumers in Addis Ababa, Ethiopia. Cross-sectional study was conducted. A total of 398 respondents were interviewed. The source population for this study was all Addis Ababa consumers who purchase packaged food from supermarkets. The data was entered into EPI data version 3.1, and then exported to statistical package for social science (SPSS) version 22 for data management and analysis. Variable with p value $<0.25$ during the bivariate logistic regression analysis was entered into multivariate logistic regression analysis. All the 398 participants were responded to the interview (100\% response rate). From the total respondents, 203 (51\%) were males, $213(53.5 \%)$ were first degree holders, 137 (34.4\%) had own business. The mean average monthly income of the head of the house hold was 5,731 $( \pm 2,230)$ Ethiopian birr, greater than half of respondents was less than 5,131 Ethiopian birr earners, $211(53 \%)$ Mean age was $36.41( \pm 10.7)$ years, 209 (47.5\%) had good knowledge on nutrition labels whereas 178 (44.7\%) had good reading practice of nutrition label on packed food. Sex, monthly income, occupation, family size, level of education, partner level education and health status of individual were the factors associated to knowledge on food labeling information. According to this study knowledge and reading practice of nutrition label is low, therefore government should formulate action plans to create awareness on nutrition labeling among the packaged food consumers. The knowledge level and reading practice of nutrition labeling were increased with age, education level and family income.
\end{abstract}

Keywords: Addis Ababa, Knowledge, Reading Practice, Nutrition Labeling, Packed Food, Consumers

\section{Background}

Food label means any material which is printed or affixed to a packing material which provides the necessary information about a food [1-2]. The type and content of food labels are nutrition information, usage guide and shelf-life of nutritionally produced food shall be stated clearly and marked on its packaged food. The label on package food should always listed are total fat, total energy, sodium, sugars, vitamins, minerals, carbohydrates and protein [2]. Food labeling is an important tool in packaged food trade and manufacturers of packaged foods if appropriately labels nutrition information; consumers use the information in making informed food choices and improving dietary 
patterns toward heath diet [3]. Nutrition information on food labels could be a cost-effective method of communicating nutrition information to consumers because the information appears at the point of sale for most packaged foods [4].

Nutrition labeling is a valuable tool in learning how to apply nutrition information in a practical way and to provide information on food products to reinforce healthy eating practices and support consumers in their efforts to improve their healthier food choices [5]. Processed and packaged foods dominate diets in high-income countries, and their consumption in low- and middle-income countries is rapidly increasing. Compared to unprocessed foods, processed foods tend to be higher in unfavorable nutrients such as added sugar, sodium, saturated fat, and trans-fats. As part of comprehensive strategies to improve diets, improving the healthiness of processed foods would, therefore, be expected to make a significant contribution to reducing the burden of diet-related non-communicable diseases [6].

Refined foods are inexpensive, taste good, and are conveniently available. Further, people choose to purchase these foods more than fruits and vegetables. Inexpensive foods are sometimes more appealing to some people despite the potential for diet-related illness [7] and provide information about the number of kilocalories, the amount of proteins, carbohydrates, fat, and to avoid contents or ingredients that they are allergic to Education on nutrition labels. Food labels information assists consumers to better understand the nutritional value of food [8].

The link between dietary habits and obesity, the Food and Drug Administration (FDA) has attempted to introduce changes to the nutrition labels on food products to make them easier to comprehend by consumers and to improve the communication of nutrition information via food labels and important future areas of research on nutrition labeling as a tool to improve diet and reduce label complexity [9]. Nutrition information in table or grid form, usually found on the back of the food package, has been supplemented by a variety of simplified nutrition labels that appear on the front of the pack (FOP) and Various formats of FOP labels have been promoted, of which the most well-known are labels based on the guideline daily amount (GDA) concepts [10].

Poor diet is a leading cause of ill health. It has been estimated that 11.3 million deaths a year worldwide are attributable to dietary risk factors [11]; hypertension, cardiovascular diseases, overweight and obesity were listed as the number one public health problem and calorie, total fats, fatty acids, cholesterol and sodium content were seen as the most useful nutrition information. Information rated as very useful, it is apparent that the nutrition information seen as most useful relates to over consumed rather than under consumed nutrients [12].

The USDA's 2010 dietary guidelines advise Americans to control total caloric intake and reduce sodium, saturated fat, Tran's fat, cholesterol and added sugar consumption. Recent global food policy efforts have focused on providing consumers with greater access to easy-to-understand nutrition information [9].
Globally, many studies have reported that reading nutrient information from food labels influences consumers' choice of food products, brands and encourages better food consumption. Hence, promoting greater utilization of the nutrition label to regulate food and calorie intake represents an important stride towards improving dietary choices. Food industries in more developed countries provide more detailed nutrition information in food labels since they are often used as important tools for communicating dietary information to consumers [13]. Processed packaged foods dominate diets in high-income countries, and their consumption in low- and middle-income countries is rapidly increasing [6]. Consumers who read the nutrition information on packaged food tend to have a healthier diet; however some consumers find the information difficult to understand and interpret it [11] usage level of nutritional labels is more effective; consumer who is less aware of the nutritional facts would consult and read the label more carefully [14].

Half of the world's consumers were understand the nutritional labels on food, which is in Asia 60\%, Europeans (50\%) and Latin Americans (45\%); whereas only 40\% consumers check the manufacturing and expiry date on food labels before purchasing. It was found that $52.7 \%$ consumers do not check the purity markers. In addition, $52.5 \%$ consumers do not read the ingredients on food products; while $63.2 \%$ consumers do not measure the serving choice of food products while preparation the food [4]. The prevalence of nutritional reading practice of the nutrition label in Malaysia 57.6\% [15], in Iran on medical students about $89.2 \%$ were aware on nutritional labeling and $77.4 \%$ were agreed with the usefulness of the food labels. For $84 \%$ of medical students, the expiry date and storage conditions information were the most important informational cues to appear on the food labels [16].

Some African countries study show that the knowledge and reading practice nutrition information was $59.6 \%$ and $69.2 \%$ respectively in Lesotho [5], 65.4\% and $86.4 \%$ respectively in Ethiopia [2], knowledge of food label information is $79.6 \%$ in Ghana [17]. For the lowest income group, food price was the major determining factor when purchasing the types of foods they buy. A positive relationship between age of participants and nutrition information knowledge was observed. It was noted that as the level of education increased, the level of knowledge about food label increased. The level and use of nutrition knowledge when purchasing foods increased with age, education level and family income and nutrition information on food labels, and why it is important to utilize that information [5].

Increased interest in nutritional issues in recent years has been fuelled by a number of factors including lifestyle, ageing population, dietary and safety concerns. As consumers have become increasingly concerned about what they eat and how it affects their health, the food industry has responded by providing more detailed nutrition information on their food labels [18].

Therefore, findings from this study will provide 
information on the knowledge and utilization of nutrition information on food labeling and how to choice packaged foods among shoppers or consumers. The information will bring to the attention of policy makers on the need to have programs to improve consumers knowledge of food labeling information as well as the utilization of such nutritional information on food labeling. Furthermore, the findings will also bring to the attention of packaged food manufacturers and regulatory bodies to improve food labeling regulations and food label formats, and also in Ethiopia there is no enough such study has been reported, therefore, it is important for Ethiopian food and nutrition policy and food medicine health care administration and control authority to improve knowledge of consumers and the end result of this research will be provide initial base line information for further such like research. No previous studies on such like studies reported in the published literature on knowledge, reading practice and association factors of nutrition information on food labels among consumers in Addis Ababa.

\section{Methods and Materials}

\subsection{Study Area and Period}

The study was conducted in Addis Ababa city Administration which is the capital city of Ethiopia. Administratively, the city is divided in to 10 sub cities and 116 Woredas. The total area of the city is 54,000 hectares. According to the 2013 population estimation, the total population of Addis Ababa is more than 4 million. According to the recent food medicine healthcare administration and control authority (FMHACA) report there are 38 supermarkets in $10 \mathrm{sub}$ cities of Addis Ababa. The study was conducted from March 1, 2018 to March 30, 2018.

\subsection{Study Design}

Institutional based cross-sectional study was employed.

\subsection{Source and Study Population}

The source population for this study was all consumers who use processed packed food in Addis Ababa, and the study population was all Addis Ababa consumers of packaged food shoppers from selected supermarkets available during study period.

\subsection{Inclusion Criteria}

All consumers available during shopping packaged foods from selected supermarkets in Addis Ababa city and age greater than 18 years and above are participated in a study.

\subsection{Exclusion Criteria}

The study was excluded non-Ethiopian citizens since they may have different knowledge regards to reading and using nutrition labels on food labels and shoppers who purchase other materials was excluded.

\subsection{Sample Size}

The sample size was calculated by using the single population formula:-

$$
\mathrm{n}=\frac{(Z \alpha / 2)^{2} * p(1-p)}{d}
$$

Where,

$\mathrm{n}=$ total sample size before adding $10 \%$ of non-response rate.

$\mathrm{Z}=$ correspond at $95 \% \mathrm{CI}(1.96)$.

$\mathrm{P}=$ proportion of knowledge or utilization of nutrition information.

$d=$ margin of error $5 \%$.

\subsection{Study Variables}

\subsubsection{Dependent Variables}

Knowledge of nutrition labeling on packaged food among consumers and; reading practice of nutrition labeling on packaged food among consumers.

\subsubsection{Independent Variables}

Social demographic characteristics of respondents (that is sex, age, level of educational, occupation, house hold monthly income, health Status of individual).

\subsection{Sampling Procedure}

According to the recent FMHACA report there are 38 supermarkets in $10 \mathrm{sub}$ cities of Addis Ababa, and then by using simple random sampling system (that is lottery method) 3 sub cities and 9 Super markets, 3 super market from Yeka sub city, 2 super market from Kolfe karenyo sub city and 4 supermarket from Gulale sub city, and then the number of sample size required for each super market was allocated equally 45 respondents (shoppers) were interviewed in order to attain the final working sample size of 398 respondents.

\subsection{Data Collection Tools}

Data was collected by using the structured questionnaire that was adapted from different literatures. The questionnaire was first prepared in English and then translated in to Amharic then back to English for data analysis.

\subsection{Data Collection Procedures}

Two Bachelor of Science (BSc) junior public health professionals (for data collection) and one BSc senior Environmental health professional (for supervisor) were trained for one day on data collection procedures. A structured questionnaire containing both open and close ended questions was used to collect information on the study variables. Respondents were asked how much they know, and reading practice of nutrition labeling available information on packed food. By using the flow of packed food shoppers; the total number of shoppers from selected 9 supermarkets, from each supermarket 13 respondents per day per 
supermarket were needed. In one month during data collection period, daily every $5^{\text {th }}$ person after shopping packed food at the exit of the main gate was interviewed until the required sample size was reached.

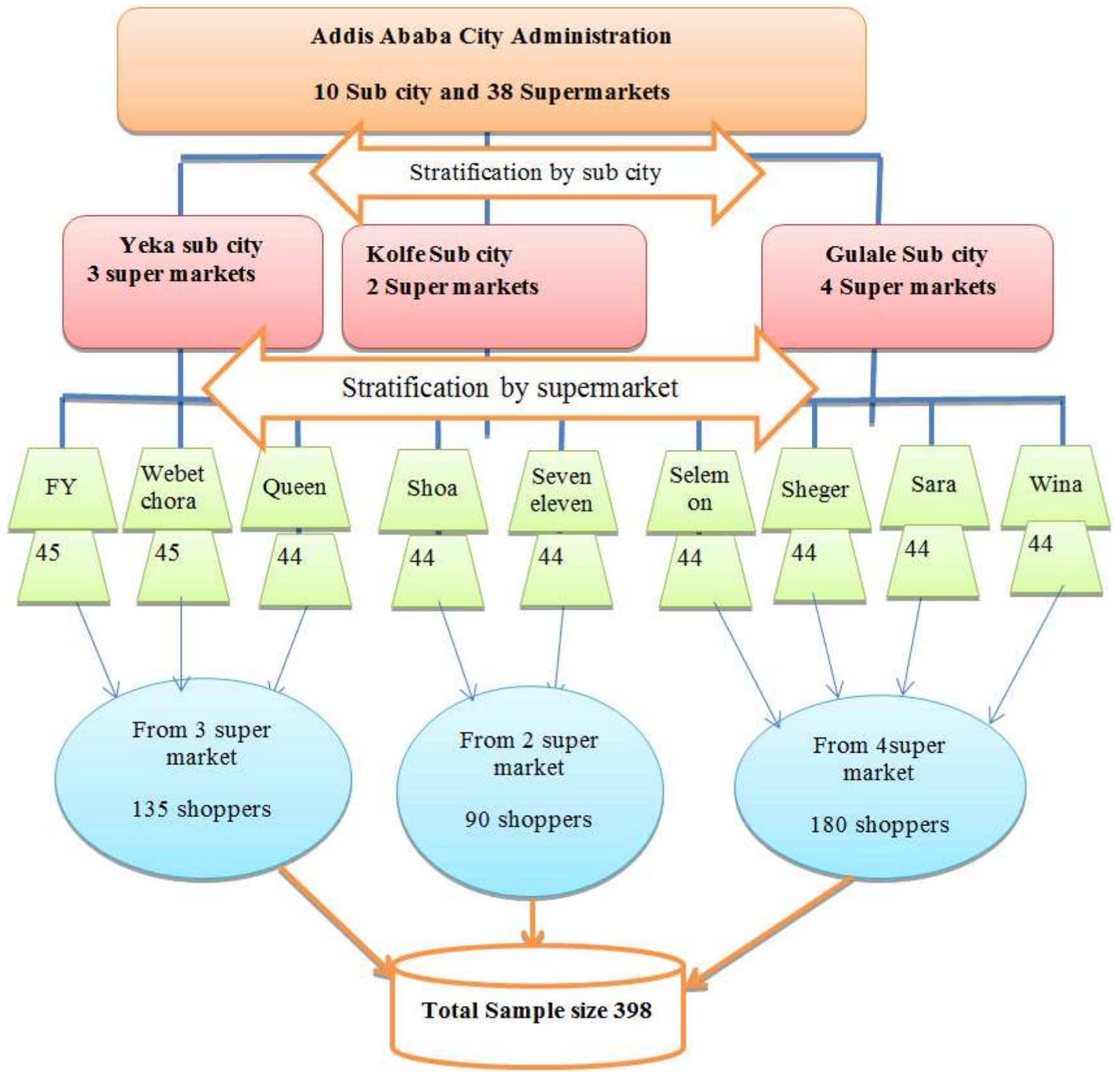

Figure 1. Schematic presentation of sampling procedure to select the study population.

\subsection{Operational Definition}

1. Food labeling: - Includes any written, printed or graphic matter that is present on the label and exactly explain the food.

2. Good knowledge: - refers to consumers who scored the mean and above the mean value of the total knowledge questions value.

3. Low knowledge: - refers to consumers who scored below the mean of the total knowledge questions value.

4. Good reading practice of nutrition label information: refers to consumers who scored the mean and above the mean value of the total reading practice of nutrition label question value.

5. Low Reading practice of nutrition label information: Refers to consumers who scored below the mean of the total reading practice questions value.

6. Food additive: - means any substance added to food to improve its taste, color, preservation or appearance and which is considered to become a component of food.

7. Adulteration: - means adding any foreign substance or ingredient to a food for commercial purpose or to be served for the public in any way or medicine other than its content or by substituting its content in whole or in part by such other substance or by storing or manufacturing it under unsanitary conditions whereby it 
may have been contaminated.

\subsection{Data Quality Assurance}

For data quality control purpose, the data collectors were rained for one day before the data collection and supervised during the data collection period. Pretest and demonstration of instrument were performed on 5\% of the sample respondents at Queen Super market. Each questionnaire was checked for completeness, missed values and unlikely responses; those incomplete questionnaires was checked and completed. Principal investigator and supervisors was made spot-checking and reviewing the completed questionnaires by the data collectors ensures completeness and consistency of the information collected.

\subsection{Data Analysis Procedures}

The data was entered into EPI data, and then exported to SPSS version 22 for data management and analysis. Descriptive statistics of percentages mean and frequency distribution using tables and figures were carried out. In addition, data were analyzed to identify significant variables and then the significant variables will be taken to Odds ratio with $95 \%$ confidence intervals and significance level of $5 \%$ was used to see the knowledge and use of nutritional information on food labeling. Multivariate logistic regression analysis was carried out to identify statistically significant variables.

\subsection{Ethical Considerations}

Before conducting the study ethical clearance was obtained from Bahirdar University, school of research and graduate studies and research and ethics committee (REC) to Addis Ababa city Administration Health Bureau and after getting permission from Addis Ababa city Administration Health Bureau to participate in the study, and then final letter was written to Gulale, Kolfekeranio and Yeka Sub City Food Medicine and Health care Administration and Control Office. Participant's right to selfdetermination and autonomy was respected, study participants was given any information they need, verbally and in written prior to a self-administration; the right of respondent to refuse; answer for few or all questions were respected. Omitting names of the participant from the questionnaire and as no personal details was recorded or produced on any documentation related to the study that help to assure confidentiality of the information and respondents. Participation was voluntarily and participant can withdraw from the study at any time without explanation and without penalty or loss of benefit.

\section{Result}

\subsection{Socio Demographic and Economic Characteristics of Respondents}

A total of 398 respondents were participated and with response rate of $100 \%$. The results of the study indicated that male $203(51 \%)$, and female 195 (49\%). A mean age of respondents was $36.41( \pm 10.7)$ years. With regard to education level, most of the respondents were 213 (53.5\%) had first degree education. About one third of participants' had own business 137 (34.4\%). The mean average monthly income of the head of the house hold earns 5,731 $( \pm 2,230)$ ETB, greater than half of respondents $211(53 \%)$ was earned $<5,731$ ETB and 187 (47\%) of them earned $>=5131 \mathrm{ETB}$. Family size $<5$ were 306 (76.9\%) and $>=5$ were 92 (23.1\%). Partner education level of respondents was first degree holders $233(58.5 \%)$ [Table 1].

Table 1. Demographic and economic characteristics of participants $(N=398)$.

\begin{tabular}{|c|c|c|c|}
\hline Variables & & Frequency & $\%$ \\
\hline \multirow{2}{*}{ Sex } & Male & 203 & 51.0 \\
\hline & Female & 195 & 49.0 \\
\hline \multirow{10}{*}{ Age Category } & $15-19$ & 3 & .8 \\
\hline & $20-24$ & 35 & 8.8 \\
\hline & $25-29$ & 75 & 18.8 \\
\hline & $30-34$ & 86 & 21.6 \\
\hline & $35-39$ & 65 & 16.3 \\
\hline & $40-44$ & 55 & 13.8 \\
\hline & $45-49$ & 20 & 5.0 \\
\hline & $50-54$ & 31 & 7.8 \\
\hline & $55-59$ & 11 & 2.8 \\
\hline & $>60$ & 17 & 4.3 \\
\hline \multirow{5}{*}{ Education level } & Elementary (grade 1-8) & 6 & 1.5 \\
\hline & Secondary (grade 9-12) & 28 & 7.0 \\
\hline & Diploma & 113 & 28.4 \\
\hline & Degree & 213 & 53.5 \\
\hline & masters and above & 38 & 9.5 \\
\hline \multirow{6}{*}{ Occupation } & Government Employed & 103 & 25.9 \\
\hline & Private Employed & 105 & 26.4 \\
\hline & own Business & 137 & 34.4 \\
\hline & House wife & 30 & 7.5 \\
\hline & Student & 20 & 5.0 \\
\hline & Others & 3 & 0.8 \\
\hline \multirow{3}{*}{$\begin{array}{l}\text { Income category } \\
\text { by quartile }\end{array}$} & First quartile & 4,000 & $25 \%$ \\
\hline & Second quartile & 5,500 & $50 \%$ \\
\hline & Third quartile & 8,000 & $75 \%$ \\
\hline \multirow{8}{*}{ Family size } & 1 & 85 & 21.4 \\
\hline & 2 & 82 & 20.6 \\
\hline & 3 & 68 & 17.1 \\
\hline & 4 & 71 & 17.8 \\
\hline & 5 & 51 & 12.8 \\
\hline & 6 & 31 & 7.8 \\
\hline & 7 & 8 & 2.0 \\
\hline & 8 & 2 & .5 \\
\hline \multirow{5}{*}{$\begin{array}{l}\text { Partner Education } \\
\text { level }\end{array}$} & Elementary (grade 1-8) & 5 & 1.3 \\
\hline & Secondary (grade 9-12) & 17 & 4.3 \\
\hline & Diploma & 88 & 22.1 \\
\hline & Degree & 233 & 58.5 \\
\hline & Masters and above & 55 & 13.8 \\
\hline
\end{tabular}

\subsection{Knowledge of Nutrition Labeling on Packed Food}

Sampled respondents were requested to respond to a series of questions in order to assess their knowledge of nutrition labeling on packaged food. With regard to nutrition label around $209(52.5 \%)$ of participants had good knowledgeable on nutrition labels and 189 (47.5\%) had low knowledge [Table 2]. 
Table 2. Knowledge of nutrition labeling on packed food.

\begin{tabular}{|c|c|c|c|}
\hline Knowledge Of Nutrition Questions & Possible Response & Frequency & $\%$ \\
\hline \multirow{2}{*}{ Do you know what a food labeling } & Yes & 358 & 89.9 \\
\hline & No & 40 & 10.1 \\
\hline \multirow{2}{*}{ Do you know nutrition information } & Yes & 301 & 75.6 \\
\hline & No & 97 & 24.4 \\
\hline \multirow{2}{*}{ Do you know the importance of nutrition label } & Yes & 364 & 91.5 \\
\hline & No & 34 & 8.5 \\
\hline \multirow{2}{*}{ Nutrition information is to help to choose Healthy diet } & Yes & 364 & 91.5 \\
\hline & No & 34 & 8.5 \\
\hline \multirow{2}{*}{ Nutrition information is to help sustain or lose or to gain weight? } & Yes & 297 & 74.6 \\
\hline & No & 101 & 25.4 \\
\hline \multirow{2}{*}{ Nutrition information is limit to consume the amount of fat, sugar and cholesterol } & Yes & 337 & 84.7 \\
\hline & No & 61 & 15.3 \\
\hline \multirow{2}{*}{ Do you read information on food labels before purchasing packaged foods? } & Yes & 335 & 84.2 \\
\hline & No & 63 & 15.8 \\
\hline \multirow{2}{*}{ Do you read ingredient list on packed food } & Yes & 142 & 35.7 \\
\hline & No & 256 & 64.3 \\
\hline \multirow{2}{*}{ Food labeling is the important tool to improve diet } & Yes & 184 & 46.2 \\
\hline & No & 214 & 53.8 \\
\hline \multirow{2}{*}{ Do you know legal requirements concerning about food labeling } & Yes & 264 & 66.3 \\
\hline & No & 134 & 33.7 \\
\hline \multirow{2}{*}{ Do you know the responsible body for the food labeling issues? } & Yes & 264 & 66.3 \\
\hline & No & 134 & 33.7 \\
\hline \multirow{2}{*}{ Do you know exactly the Gregorian calendar to identify expire and manufacture date? } & Yes & 352 & 88.4 \\
\hline & No & 46 & 11.6 \\
\hline \multirow{2}{*}{ Kilocalorie is the unit measurement of energy get from diet } & Yes & 325 & 81.7 \\
\hline & No & 73 & 18.3 \\
\hline \multirow{2}{*}{ Fat food products is provides high energy } & Yes & 122 & 30.7 \\
\hline & No & 276 & 69.3 \\
\hline \multirow{2}{*}{ Do you know Lack of knowledge of nutritional labels leads to potential health problem } & Yes & 381 & 95.7 \\
\hline & No & 17 & 4.3 \\
\hline \multirow{2}{*}{ High amount of Saturated fats content foods are Cause more health problem } & Yes & 142 & 35.7 \\
\hline & No & 256 & 64.3 \\
\hline Good Knowledge & & 209 & 52.5 \\
\hline Low knowledge & & 189 & 47.5 \\
\hline
\end{tabular}

\subsection{Reading Practice of Nutrition Labels on Packaged Food}

The overall mean reading practice of respondents was 2.51 $( \pm 0.89)$. The study revealed that around $178(44.7 \%)$ of consumers had good reading practice and $220(55.3 \%)$ had low reading practice. The respondents perceived different kinds of information (available on the food label) as important to read and use information, in spite of that they don't see or read that information listed while purchasing. Though, on the whole, majority of the respondents don't check available information on packaged food before buying packed food products always that is $81.4 \%$ check the expiry date, $72.6 \%$ check net content with price, $42.7 \%$ check instruction for cooking, $40.2 \%$ use ingredient list, $38.9 \%$ total carbohydrate, $36.7 \%$ total fat content are the major focus to read always and about the rest of things they were found least bothered.

In this study, those participants who had good reading practice were answers greater than or equal to 2.51 (mean) reading practice questions, and those who had low reading practice were also answering less than 2.51 reading practice questions. Each and over all reading practice question score is shown in the tables 3 and 4 below.

Table 3. Over all reading practice of nutrition labeling on packed food.

\begin{tabular}{|c|c|c|c|c|c|}
\hline \multirow[b]{2}{*}{ How often you Read nutrition label } & \multicolumn{5}{|c|}{ Possible Answer } \\
\hline & $\begin{array}{l}\text { Never } \\
\text { Count (\%) }\end{array}$ & $\begin{array}{l}\text { Sometime } \\
\text { Count (\%) }\end{array}$ & $\begin{array}{l}\text { Half of the time } \\
\text { Count }(\%)\end{array}$ & $\begin{array}{l}\text { Most of the time } \\
\text { Count (\%) }\end{array}$ & $\begin{array}{l}\text { Always } \\
\text { Count (\%) }\end{array}$ \\
\hline Name \& Country of the manufactured & $91(22.9)$ & $174(43.7)$ & $36(9)$ & $69(17.3)$ & $28(7)$ \\
\hline Manufacturing and Expiry date & $40(10.1)$ & $34(8.5)$ & $12(3)$ & $142(35.7)$ & $170(42.7)$ \\
\hline Total carbohydrate & $104(26.1)$ & $139(34.9)$ & $57(14.3)$ & $73(18.3)$ & $25(6.3)$ \\
\hline Total fat & $110(27.6)$ & $142(35.7)$ & $59(14.8)$ & $62(15.6)$ & $25(6.3)$ \\
\hline Salt, sodium content & $118(29.6)$ & $148(37.2)$ & $55(13.8)$ & $53(13.3)$ & $24(6)$ \\
\hline Instructions for use and cooking & $96(24.1)$ & $132(33.2)$ & $58(14.6)$ & $70(17.6)$ & $42(10.6)$ \\
\hline Net content with price & $49(12.3)$ & $60(15.1)$ & $50(12.6)$ & $139(34.9)$ & $100(25.1)$ \\
\hline
\end{tabular}




\begin{tabular}{|c|c|c|c|c|c|}
\hline \multirow[b]{2}{*}{ How often you Read nutrition label } & \multicolumn{5}{|c|}{ Possible Answer } \\
\hline & $\begin{array}{l}\text { Never } \\
\text { Count (\%) }\end{array}$ & $\begin{array}{l}\text { Sometime } \\
\text { Count (\%) }\end{array}$ & $\begin{array}{l}\text { Half of the time } \\
\text { Count }(\%)\end{array}$ & $\begin{array}{l}\text { Most of the time } \\
\text { Count (\%) }\end{array}$ & $\begin{array}{l}\text { Always } \\
\text { Count (\%) }\end{array}$ \\
\hline Warning (e.g. not suitable for diabetes) & $137(34.4)$ & $124(31.2)$ & $58(14.6)$ & $47(11.8)$ & $32(8)$ \\
\hline Nutrition claims? & $167(42.0)$ & $130(32.7)$ & $50(12.6)$ & $34(8.5)$ & $17(4.3)$ \\
\hline Daily value of nutrients needs & $183(46.0)$ & $116(29.1)$ & $51(12.8)$ & $30(7.5)$ & $18(4.5)$ \\
\hline Compare depending on nutritional content & $184(46.2)$ & $114(28.6)$ & $51(12.8)$ & $26(6.5)$ & $23(5.8)$ \\
\hline Good reading practice (count $(\%)$ ) & & $178(44.7 \%)$ & & & \\
\hline Low reading practice (count $(\%)$ ) & & $220(55.3 \%)$ & & & \\
\hline
\end{tabular}

Measure scale: - 1-never read, 2-some times read 3-half of the time read, 4-most of the time read and 5-always read.

Table 4. Mean reading practice of nutrition labeling from packed food.

\begin{tabular}{llll}
\hline Reading practice questions & Mean & \% & Std. Deviation \\
\hline Name and Country of the manufactured & 2.42 & 33.4 & 1.214 \\
Ingredient list & 2.53 & 40.2 & 1.249 \\
Expiry date & 3.92 & 81.4 & 1.305 \\
Total carbohydrate & 2.44 & 38.9 & 1.231 \\
Total fat & 2.37 & 36.7 & 1.216 \\
Vitamins content & 2.35 & 36.4 & 1.188 \\
Salt or sodium content & 2.29 & 33.2 & 1.310 \\
Instructions for use and cooking & 2.57 & 42.7 & 1.340 \\
Net content with price & 3.45 & 72.6 & 1.270 \\
Warning (e.g. not suitable for diabetes) & 2.28 & 34.4 & 1.129 \\
Nutrition claims? & 2.01 & 25.4 & 1.139 \\
Daily value of nutrients needs & 1.95 & 24.9 & 1.172 \\
Compare depending on nutritional content & 1.97 & 25.1 & \\
Over all mean reading practice & 2.51 & & \\
\hline
\end{tabular}

\subsection{Bivariate Analysis of Association Factors on Knowledge of Nutrition Labeling}

After managing for covariates only sex, educational level, monthly income and partner educational level were significantly associated with knowledge on nutrition labeling. The odds of knowledge of nutrition labeling of male respondents $(\mathrm{AOR}(95 \%$ of $\mathrm{CI}))=1.22(0.79-1.88)$ were 1.22 times higher than female respondents and the odds of the knowledge of nutrition labeling of those diploma and above holders $(\mathrm{AOR}(95 \%$ of $\mathrm{CI}))=6.68(2.39-18.64)$ were 6.68 times higher than those grade 1-12 complete and the odds of knowledge of nutrition labeling those $>=5731$ ETB monthly income earners $(\mathrm{AOR}(95 \%$ of $\mathrm{CI}))=2.06(1.34-3.18)$ were 2.06 times higher than those $<5731$ ETB monthly income earns. This study results indicated that those who have good knowledge of nutrition labeling on packed food are more likely to be in the group categories of high income earners, own business occupation, high level of education. Therefore income, occupation, education level and health status of individual variables are more associated factors on knowledge of nutrition labeling [Table 5].

Table 5. Bivariate analysis of association factors on knowledge of nutrition labeling.

\begin{tabular}{|c|c|c|c|c|}
\hline \multirow{2}{*}{ Variables } & \multicolumn{4}{|c|}{ Knowledge of Nutrition labeling } \\
\hline & Good knowledge count (\%) & Low knowledge count (\%) & COR $(95 \%$ of $\mathrm{CI})$ & AOR $(95 \%$ of $\mathrm{CI})$ \\
\hline \multicolumn{5}{|c|}{ Sex of respondents (398) } \\
\hline Male & $109(53.7)$ & $94(46.3)$ & $1.1(0.74-1.53)$ & $1.22(0.79-1.88)$ \\
\hline Female & $100(51.3)$ & $95(48.7)$ & 1 & 1 \\
\hline \multicolumn{5}{|l|}{ Age category by mean } \\
\hline$<36$ years & $118(51.5)$ & $111(48.5)$ & 1 & 1 \\
\hline$>=36$ years & $91(53.8)$ & $78(46.2)$ & $1.1(0.74-1.63)$ & $0.86(0.52-1.45)$ \\
\hline \multicolumn{5}{|c|}{ Education level of respondents (398) } \\
\hline Grade $1-12$ complete & $5(14.3)$ & $30(85.7)$ & 1 & 1 \\
\hline Diploma and above & $204(56.2)$ & $159(43.8)$ & $7.7(2.92-20.29)^{* *}$ & $6.68(2.39-18.6)$ \\
\hline \multicolumn{5}{|c|}{ Occupation of respondents (398) } \\
\hline Employed & $188(54.5)$ & $157(45.5)$ & $1.83(1.01-3.29)$ & $0.82(0.42-1.59)$ \\
\hline Un Employed & $21(39.6)$ & $32(60.4)$ & 1 & 1 \\
\hline \multicolumn{5}{|c|}{ Monthly Income of head of households of respondents (398) } \\
\hline$<5,731$ & $92(43.6)$ & $119(56.4)$ & 1 & 1 \\
\hline$>=5,731$ & $117(62.6)$ & $70(37.4)$ & $2.16(1.44-3.23)^{* *}$ & $2.06(1.34-3.18)$ \\
\hline \multicolumn{5}{|c|}{ Family size of respondents (398) } \\
\hline$<5$ & $152(49.8)$ & $153(50.2)$ & $1.64(1.02-2.64)^{*}$ & $0.53(0.29-0.97)$ \\
\hline$>=5$ & $57(62)$ & $35(38)$ & 1 & 1 \\
\hline \multicolumn{5}{|c|}{ Partner education levels of respondents (398) } \\
\hline Grade $1-12$ complete & $5(22.7)$ & $17(77.3)$ & 1 & 1 \\
\hline Diploma and above & $189(47.5)$ & $172(45.7)$ & $4.01(1.45-11.10)^{* *}$ & $2.47(0.81-7.50)$ \\
\hline
\end{tabular}




\begin{tabular}{lllll}
\hline \multirow{2}{*}{ Variables } & \multicolumn{3}{l}{ Knowledge of Nutrition labeling } & \\
\cline { 2 - 5 } & Good knowledge count (\%) & Low knowledge count (\%) & COR (95\% of CI) & AOR (95\% of CI) \\
\hline Health status of individual of respondents & & & \\
Normal & $200(52.8)$ & $179(47.2)$ & 1 & 1 \\
Chronic diseased & $9(47.4)$ & $10(52.6)$ & $1.24(0.50-3.12) *$ & $0.66(0.25-1.73)$ \\
\hline
\end{tabular}

* Significant at $\mathrm{p}$-value $<0.05,{ }^{*}$ Significant at $\mathrm{p}$-value $<0.01$

\section{Discussion}

The result of this study indicated that the overall knowledge of nutrition label on packed food among consumers in Addis Ababa was 52.5\% which was lower than study done in Lesotho $59.6 \%$ (5), in Ghana 79.6\%(17), and Ambo University on teaching staff $65.4 \%[5,17,2]$. The possible explanation for the difference might be due to the knowledge status difference between the study countries and places. The reading practice of nutrition label on packed food among consumers in Addis Ababa was $44.7 \%$ which was higher than study done in urban consumers in India (40\%) [19]. Male respondents seemed to be more aware of food labeling than female respondents. This is not similar to what was reported in United Arab Emirates [8]. The sample of respondents also composed of various education levels ranging from primary education to above masters holders, and different groups of sex, aged, occupation, family size and partner education level of respondents which influence or affect knowledge of nutrition labeling information. Similarly, study done in Lesotho and in Ghana [5, 17] results also showed that, level of education and income of respondents had statistically significant association with knowledge on nutrition labeling information.

\section{Conclusion and Recommendation}

\subsection{Conclusion}

In this study those who had good knowledge on nutrition labeling information was low and also those who had good reading practice of nutrition labeling information was low. Sex, educational level, income, family size, partner educational level, and health status of individual were determinant factors for knowledge on nutrition labeling information. From this study it was found that education level and monthly income of households were the two major associated factors of knowledge on nutrition information on packed food. The results of cross tabulation indicated that those most likely to had good knowledge on nutritional labeling information on packaged food were in the categories with high income, high education, and low family size respondents.

\subsection{Recommendation}

For Addis Ababa FMHACA

Addis Ababa Food, Medicine and Health Care Administration and Control Authority should formulate action plans to create awareness on food labeling information.

For researchers

Further studies should be conducted to assess knowledge and reading practice of nutrition labeling on packaged food, health claims and nutritional information.

For supermarkets

The owners of supermarket should always check and separate those expired product from others.

\section{List of Abbreviations}

BSc:-Bachelor of Science

CDC:-Communicable disease control and prevention

ETB:-Ethiopian birr

FDA:-Food and drug administration

FMHCACA:-Food medicine healthcare administration and control authority

FOP:-Front of packaged

GDA:-Guideline daily amount

PI:-Principal investigator

REC:-Research and ethics committee

SM:-Super market

SPSS:-Statistical package for social science

SRS:-Simple random sampling

WHO:-World health organization

\section{Declarations}

\section{Ethics Approval and Consent to Participate}

Before conducting the study ethical clearance was obtained from Bahirdar University, School of Research and Graduate Studies and Research and Ethics Committee (REC) to Addis Ababa City Administration Health Bureau, and then after getting permission from Addis Ababa City Administration Health Bureau to participate in the study, and then finally letter was written to Gulale, Kolfekeranio and Yeka Sub City Food Medicine and Health care Administration and Control Office. Participant's right to selfdetermination and autonomy was respected, study participants was given any information they need, verbally and in written prior to a self-administration; the right of respondent to refuse; answer for few or all questions were respected. Omitting names of the participant from the questionnaire and as no personal details was recorded or produced on any documentation related to the study that help to assure confidentiality of the information and respondents. Participation was voluntarily and participant can withdraw from the study at any time without explanation and without penalty or loss of benefit.

\section{Availability of Data and Materials}

The finding of this study was generated from the data 
collected and analyzed based on the stated methods and materials. The original data supporting this finding are available from the corresponding author on reasonable request.

\section{Competing Interests}

"The authors declare that they have no competing interests"

\section{Authors' Contributions}

EF participated in the design of the study, performed the data collection and statistical analysis, and served as the corresponding author of the manuscript. RW and $\mathrm{ZK}$ supervised the study, ensured quality of the data, and assisted in the analysis and interpretation of the data. All authors read and approved the manuscript.

\section{Authors' Information}

$\mathrm{EF}$ is Addis Ababa food medicine and healthcare administration and control authority, health and health related facility inspection team leader, Addis Ababa, Ethiopia.

RW is Maternal and Child Health Expert at SendafaBeke town, Oromia regional state, central Ethiopia.

ZK is Public health specialist at East Wollega Zonal Health Office of Oromia regional state, western Ethiopia.

\section{Acknowledgements}

We are grateful to Addis Ababa city health bureau and Addis Ababa food medicine health care administration and control authority, for their unfailing support and guidance during the whole activities of this thesis. We also indebted for the study participants for their co-operation without which this study could not have been possible.

\section{References}

[1] Efmhca. Federal Negarit Gazeta Of The Federal Democratic Republic Of Ethiopia. Negarit Gaz. 2010.

[2] Mansingh Jp, Bayissa Dd, Erena Fa. Research Article Awareness Of Nutritional Information And Trans-Fat Trans Fat In Food Label Among Teaching Staff Of Ambo University, Ambo, Ethiopia. 2015.

[3] Afsane Ahmadi, Pariya $T$ Torkamani Z. Nutritional Knowledge: Application And Perception Of Food Labels Among Women. 2013.

[4] Neeta Deshmukh Rg. Food Label Reading Knowledge And Understanding Among Consumers. 2017; 71-2.
[5] Mahgoub S. Awareness And Use Of Nutrition Information On Food Packages Among Consumers In Maseru (Lesotho). African J Food African J Food Agric Nutr Dev. 2007; 7 (6): 116.

[6] Incorporating Added Sugar Improves The Performance Of The Health Star Rating Front-Of-Pack Labelling System In Australia.

[7] Pilgrim-Hector J, Pilgrim-Hector J. Perception Of Nutrition And Utilization Of Healthy Food Ideas When Making Food Choices Walden University. 2016.

[8] Sidiga Washi. Consumer's Awareness Of Food Labeling In The United Arab Emirates. 2011.

[9] Roberto Ca, Khandpur N. Improving The Design Of Nutrition Labels To Promote Healthier Food Choices And Reasonable Portion Sizes. Int J Obes [Internet]. 2014; 38 (S1): S25-S33. Available From: Http://Dx.Doi.Org/10.1038/Ijo.2014.86.

[10] Grunert Kg, Wills Jm, Ferna L, Fernández-Celemín L. Nutrition Knowledge, And Use And Understanding Of Nutrition Information On Food Labels Among Consumers In The Uk §. Appetite. 2010; 55: 177-89.

[11] Kaur A, Scarborough P, Rayner M. A Systematic Review, And Meta-Analyses, Of The Impact Of Health-Related Claims On Dietary Choices. 2017; 1-17.

[12] Stokes C. Nutrition American Industry, Labeling And Public Health : Survey Of Institute Of Nutrition Members, Food And Consumers 13. 1982.

[13] Aboulnasr K, Gulf F. The Role Of Self - Efficacy, Response Efficacy And Nutrition Knowledge In Consumers 'Utilization Of Nutrition Labels. 2013; 23 (1): 1-13.

[14] Effect Of Consumer Knowledge On Usage Of Nutritional. 2017; 8 (2).

[15] Norazlanshah H, Muhammad I, Mashita M, Mf Fn. The Use Of Nutrition Label On Food Purchasing Decision Among University Students In Kuantan, Malaysia. 2013; 4 (1): 1-10.

[16] Malek Mahdavi A, Abdolahi P, Mahdavi R. Knowledge, Attitude And Practice Between Medical And Non-Medical Sciences Students About Food Labeling. Heal Promot Perspect. 2012; 2 (2): 173-9.

[17] Darkwa S, Sci F, Lecturer S. Knowledge Of Nutrition Facts On Food Labels And Their Impact On Food Choices On Consumers In Koforidua, Ghana: A Case Study. 2014; 27 (1): 13-7.

[18] Themba G, Tanjo J. Consumer Awareness And Usage Of Nutrition Information In Botswana. 2013; 1 (1). Available From: Www.Macrothink.Org/Bmh.

[19] Vemula Sr, Gavaravarapu Sm, Vardhana V, Mendu R, Mathur P, Avula L. Use Of Food Label Information By Urban Consumers In India - A Study Among Supermarket Shoppers. 2017; 17 (9): 2104-14. 